\title{
Bone mass predictors in a large cohort of children with juvenile idiopathic arthritis (JIA)
}

\author{
FF Falcini ${ }^{* 1}$, CS Capannini ${ }^{1}$, TG Tonini ${ }^{3}$, NF Nacci ${ }^{1}$, SG Simonini², \\ CR Cimaz ${ }^{2}$ and SS Stagi ${ }^{2}$
}

Address: ${ }^{1}$ Department of BioMedicine, Division of Rheumatology, Transition Unit, University of Florence, Florence, Italy, ${ }^{2}$ Department of Paediatrics, Rheumatology and Endocrinology Units, University of Florence, Florence, Italy and ${ }^{3}$ Oncology Prevention Unit and CSPO, University of Florence, Florence, Italy

* Corresponding author

from I5 ${ }^{\text {th }}$ Paediatric Rheumatology European Society (PreS) Congress

London, UK. 14-17 September 2008

Published: 15 September 2008

Pediatric Rheumatology 2008, 6(Suppl I):P66 doi:10.1 I86/1546-0096-6-SI-P66

This abstract is available from: http://www.ped-rheum.com/content/6/SI/P66

(C) 2008 Falcini et al; licensee BioMed Central Ltd.

\section{Purpose}

Low bone mass has been reported in children with JIA. We wanted to assess areal bone mineral density (BMD) in our cohort of patients and correlate the results with clinical data.

\section{Methods}

The study population included 162 pts (113 F and $49 \mathrm{M}$, mean age $10.6 \pm 3.1 \mathrm{yrs}$ ) affected with JIA: 77 oligoarticular, 48 polyarticular RF-, 15 systemic, and 22 enthesitisrelated arthritis (ERA) onset. All patients underwent bone mass evaluation by DXA at lumbar spine (L2-L4). DXA values were correlated with JIA category, age at onset, disease duration, ESR, CRP, flare rate, and medications. Ageand sex-specific reference values from an age-matched healthy population were used to calculate z-scores. Twoway analysis of variance was used to determine whether the DXA z-score correlated with disease category, medications, age at onset, disease duration.

\section{Results}

The whole group of JIA pts showed lower DXA z-scores (systemic $\mathrm{p}=0.0012$; oligoarticular $\mathrm{p}=0.0072$; polyarticular $\mathrm{p}=0.0002)$, except ERA ( $\mathrm{p}=\mathrm{NS}$ ) when compared to controls. DXA z-scores significantly correlated with JIA subtype: systemic had lower $z$-score than oligoarticular ( $p$ $=0.015)$ and ERA $(\mathrm{p}=0.001)$, while polyarticular pts had lower $\mathrm{z}$-score in comparison to ERA ( $\mathrm{p}=0.009)$.
In the group with oligoarticular onset, patients treated with MTX plus corticosteroids had a higher z-score than those treated with only corticosteroids $(p=0.024)$.

\section{Conclusion}

JIA patients, in particular with polyarticular and systemic onset show a lower DXA z-score in comparison to controls while in ERA DXA values are comparable to controls. Together with sex, disease duration seems the main factor modifying DXA value. 